\title{
Don Ricardo Palma y su homenaje marmóreo a la casa natal de Miguel Grau en Piura
}

\author{
Por Juan Carlos Adriazola Silva
}


Doctor en Ciencias de la Educación por la Universidad Nacional de Piura y magíster en Investigación y Docencia por la Universidad Nacional Pedro Ruiz Gallo de Lambayeque. 
Aunque mi participación en el Encuentro anual de "ReVisión de las Tradiciones" ha venido siendo reiterada en este Instituto que lleva como timbre de orgullo el nombre del padre de la Tradiciones peruanas, mi presencia en esta oportunidad viene enaltecida con la designación honrosísima, pero inmerecida, de que soy objeto al ser admitido como "Miembro Correspondiente" del Instituto Ricardo Palma, ello gracias a la extrema generosidad de los dos principales artífices que lo impulsan, su presidente, Dr. Manuel Pantigoso Pecero, y el rector, Dr. Iván Rodríguez Chávez; y digo extrema generosidad porque no otra es la razón que puede explicar tal nombramiento que me hace, de hecho, el más humilde colega de notables investigadores palmistas que tanto en el ámbito nacional como en el internacional honran a esta corporación y a la casa del saber que la alienta: la Universidad Ricardo Palma. Gratitud eterna, lealtad sin límite y trabajo esforzado son las ofrendas inmarcesibles que esta tarde puedo dejar a los pies de nuestro patrono institucional, las cuales nacen con sinceridad de mi corazón e intelecto como la única manera que conozco de retribuir a tan magnánima muestra de amistad.

En esta oportunidad vengo a abordar la vida de dos personajes ilustres en la historia de nuestro país: don Ricardo Palma Soriano y don Miguel Grau Seminario, cada uno de ellos importante en lo que mejor supieron hacer: el primero, escribir y dar lustre a las letras nacionales el segundo, navegar con pericia sobre los mares y, en las horas más aciagas de la patria, 
combatir como marino hasta entregar la vida para salvar la dignidad del Perú. Sin embargo, hay en estos dos personajes, puntos de encuentro, como por ejemplo, su pertenencia a la Marina; la contemporaneidad que les tocó vivir en la capital de la República; su amor a la patria; su relación con la ciudad norteña de Piura y, particularmente, con Paita ${ }^{1}$, ciudad-puerto en la que estuvieron, cada uno en su tiempo, durante la primera mitad del siglo XIX.

¿Cómo nace el interés por vincular a estos dos personajes señeros de la vida nacional? He aquí la respuesta. Tomé posesión efectiva del cargo de Director de la Casa Museo Gran Almirante Grau de Piura en ceremonia oficial que se realizó el 21 de mayo de 2013, con motivo del centésimo trigésimo cuarto aniversario del combate naval de Iquique, lo que constituyó para mí un alto honor y un privilegio inmerecido; pero, a la vez, generó en mí una preocupación grande por la responsabilidad que entrañaba el cargo y el compromiso que, a partir de esa fecha, asumía no solo frente a la Marina de Guerra del Perú sino con mi ciudad natal y el país, al dirigir una institución considerada Patrimonio Monumental de la Nación, según Ley N 10146 de 30 diciembre de 1944.

$\mathrm{Al}$ ir compenetrándome de los principales acontecimientos que han signado la Casa Museo a lo largo de su historia, advertí que en el 2014 se cumplirían los primeros 50 años de creación de la institución, pues fue inaugurada solemnemente el 27 de julio de 1964. Era, por tanto, imprescindible prepararse para la ocasión, y así se lo hice saber oportunamente a las autoridades de la Marina de Guerra. Medio siglo de existencia merecía

I Un trabajo notable sobre lugares, personajes y costumbres que Ricardo Palma observó en Piura y Paita, lo encontramos en: Miró Quesada Sosa, Aurelio. Piura en las tradiciones de Palma. Piura, Universidad de Piura (Colección Algarrobo $\left.\mathrm{N}^{\circ} 11\right), 1973$. 
una recordación especial, de tal modo que puse manos a la obra, y al pensar en cual debería ser, entre otras actividades planificadas, la más perdurable y tangible de todas, surgió la idea de hacer un libro conmemorativo del primer jubileo de la casa donde se venera de forma cotidiana y perpetua la memoria del "Caballero de los Mares" y a quien la voluntad popular de fines del siglo XX había elegido con el honrosísimo título de "El Peruano del Milenio".

Uno de los capítulos que contendrá justamente ese libro conmemorativo hablará del primer homenaje que la casa natal de don Miguel Grau en Piura recibió en 1906, nada más y nada menos que del Padre de las Tradiciones, el ilustre don Ricardo Palma, quien a la distancia, siendo Director de la Biblioteca y Archivo Nacional, se tomó el trabajo de mandar labrar una placa de mármol para conmemorar el lugar exacto del nacimiento del epónimo héroe.

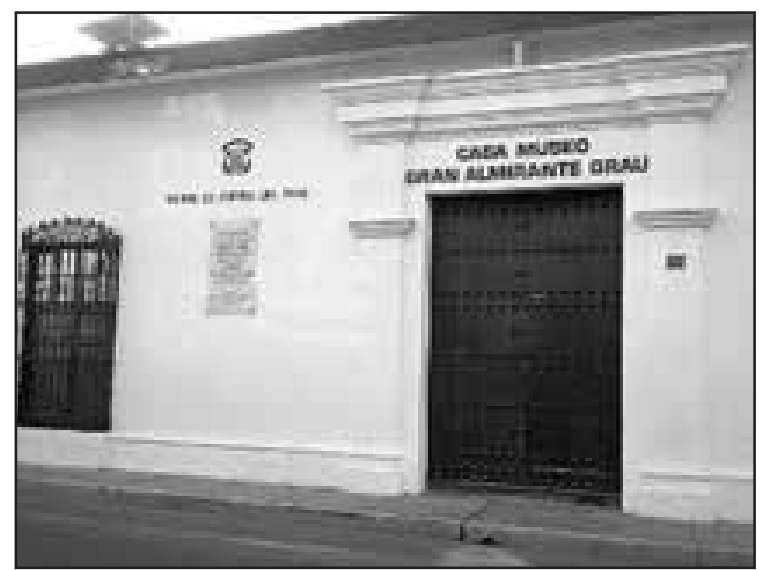

Don Ricardo Palma y su homenaje marmóreo a la casa natal de Miguel Grau, en Piura. 


\section{Parte de una misma familia: la Marina de Guerra del Perú}

Aunque en el imaginario popular pocas veces se relaciona la figura de Ricardo Palma con la de Miguel Grau, quizá porque lo más saltante de sus vidas se da en campos diferentes: uno en la literatura, el otro en la marina profesional, la verdad es que entre ellos existen varios puntos en común que no pueden dejarse de advertir. Hablando de edades, solo hay una diferencia de casi año y medio de vida entre ambos. Don Ricardo Palma nació en Lima el 7 de febrero de 1833. Miguel Grau nació en San Miguel de Piura el 27 de julio de 1834. Sus tempranas infancias transcurrieron en sus respectivas ciudades natales. En su niñez, sin embargo, ambos disfrutaron más del afecto paterno que del materno ${ }^{2}$.

Con el pasar de los años, más específicamente en 1854, según ha puntualizado Carlos Zúñiga Segura, encontramos a Palma y a Grau como jóvenes al servicio de la Marina de Guerra del Perú ${ }^{3}$, uno como empleado civil del área administrativa y contable (Oficial $3^{\circ}$ del Cuerpo Político de la Armada), el otro como un joven guardiamarina (esto es, se encontraba en proceso de formación necesaria antes de convertirse formalmente en Alférez de Fragata). En los dos casos, la Marina de Guerra se constituyó en la institución castrense que los acogió en su seno como parte de una gran familia.

2 Según Oswaldo Holguín Callo, quien ha estudiado de forma documental y en profundidad la infancia del niño Ricardo Palma, este tuvo muchos sinsabores y falta de afecto materno. Cfr. Holguín... Tiempos de infancia y bohemia. Ricardo Palma (1833-1860). Lima, Fondo Editorial de la PUCP, 1994, Cap. I, pp.19-94. En el caso del niño Miguel Grau ocurrió algo similar; aunque ello marcaría su vida de modo indeleble no hizo de él un ser amargado, huraño ni misógino. Cfr. De la Puente... Miguel Grau. Lima, Instituto de Estudios Histórico Marítimos del Perú, 2003, Cap. II, pp. 11-34.

3 Cfr. Zúñiga Segura, Carlos. Ricardo Palma en la Marina. Lima, Editorial de la Universidad Ricardo Palma, 2004, p.47. 
La primera pregunta que nace de este paralelismo vital es: ¿en la Marina se conocieron y se trataron personalmente Ricardo Palma y Miguel Grau? Para dar respuesta a esta incógnita tratamos de indagar en diversa bibliografía en el Archivo Histórico de la Marina y en los epistolarios de Palma publicados hasta la fecha, con el propósito de encontrar algunos documentos oficiales, papeles personales o cartas de ida y vuelta que nos informaran acerca de alguna proximidad amical o, cuando menos, de algún nivel de trato interpersonal. Si bien es cierto la búsqueda documental fue poco fructuosa, nos llevó, en cambio, a adentrarnos en un acontecimiento histórico en el que sí se sabe participaron ambos: la revolución vivanquista contra Ramón Castilla, acaecida en el año 1856. Sobre el particular, Oswaldo Holguín relata:

"El $1^{\circ}$ de noviembre de 1856 , por medio de un cabildo abierto, el pueblo de Arequipa dirigido por Domingo Gamio y Diego Masías, desconoció al Gobierno y proclamó Supremo Jefe Regenerador al General Manuel Ignacio de Vivanco (1806-1873). Los revolucionarios acusaron a Castilla de haber faltado a los principios fundamentales del movimiento que culminara en La Palma y de haberse vuelto dictador dando la espalda a los postulados liberales que lo habían llevado al poder: también criticaron la Constitución recién jurada por 'anómala, antirelijiosa [sic], inoportuna y contraria a la opinión nacional', la forma en la que se hacía la abolición de la esclavitud y el tributo indígena (...) El jefe de la rebelión (...) representaba a la multitud de descontentos, resentidos y adversarios del régimen".

En párrafo seguido, el citado autor, refiriéndose con lujo de detalles a la participación concreta de la Marina de Guerra del Perú, expresa: 
"El 3 de noviembre, ignorantes de lo ocurrido en el sur del país, partieron del Callao hacia ese destino los vapores de guerra 'Ucayali' y 'Loa' conduciendo fuerzas militares. Palma integraba la dotación de este último. El 16, en aguas de Arica, el teniente $2^{\circ}$ Lizardo Montero encabezó la sublevación de la fragata 'Apurímac', la más poderosa unidad de la escuadra; el Alférez de Fragata Miguel Grau fue el segundo cabecilla del motín. La 'Apurímac' se trasladó a Ilo y, de inmediato, a Islay, en cuya bahía el 'Loa' estaba al ancla; era la noche del 17 y el comando de este buque pensó que se trataba del 'Ucayali'. En la madrugada del 18, ya identificada la 'Apurímac' ingresó al fondeadero; el comandante del 'Loa', Teniente $1^{\circ}$ Hercilio Cabieses, pensó que en la fragata se hallaba el Capitán de Navío José María Salcedo, jefe de la estación naval del sur, a cuyas órdenes quiso ponerse y comunicarle lo que pasaba en Arequipa. Cabieses fue recibido por Grau y llevado a presencia de Montero, quien lo puso en prisión y ordenó a aquél que hiciera venir al segundo comandante del 'Loa', Teniente $1^{\circ}$ Gaspar Selaya, el cual también cayó en la trampa. El Guardiamarina Honorato Tizón fue comisionado para abordar el buque, hacerlo rendir y encargar su mando al Teniente $2^{\circ}$ Mariano Melgar, 'a quien suponían comprometido con ellos y que en el caso que no quisieran rendirse los echarían a pique, pues tenían la artillería del costado de babor cargada a bala y metralla; no hubo necesidad de esto pues a pocos momentos se oían gritos a bordo del 'Loa' que vivaban al General Vivanco y a los Tenientes Montero y Melgar'; sin embargo, los que rehusaron unirse a la rebelión, informó Cabieses, trataron de convencer a los otros ya que no les era posible resistir, pero 'toda persuasión fue inútil y se plegaron al movimiento los Tenientes Segundos don Mariano Melgar y don Federico Lara, el Alférez de Fragata don Enrique 
Pareja, los Guardias Marinas don Ezequiel Otoya y don Gregorio Evia, el $2^{\circ}$ piloto don José Rodríguez, el contador oficial $3^{\circ}$ don Ricardo Palma y el cirujano de segunda clase don Elías Bellido"4.

Aunque los acontecimientos que se suscitaron posteriormente, parecieron darles a los revolucionarios vivanquistas un eventual triunfo (Palma inclusive fue ascendido por Vivanco a la clase superior de Oficial $2^{\circ}$ del Cuerpo Político de la Armada), la verdad es que el presidente Ramón Castilla tomó acciones rápidas para contrarrestar a los insurrectos y, al poco tiempo retomó el poder absoluto. Y la hora del escarmiento no se dejó esperar, pues en compañía de su Ministro de Guerra y Marina General Manuel Diez Canseco:

"Expidieron un decreto en cuyo párrafo considerativo se dijo que la conducta de los oficiales de las naves 'Apurímac', 'Loa', [etc.] 'ha sido indigna de los honrosos antecedentes del Cuerpo General de la Armada, por la traición y deserción en que ha [sic] incurrido faltando a sus deberes y apostatando de la Constitución política de la República que juraron obedecer y cumplir', por lo cual se les dio de baja "borrándose sus nombres del escalafón"'.

Es así como para nuestros dos personajes la aventura vivanquista llegó a su fin. A Palma le causó "grave daño" y de nada le valió el ascenso que el caudillo regenerador le concediera, ya que siguió siendo un simple Oficial de $3^{\circ}$ del Cuerpo Político de la Armada, y gracias a su oportuno y sagaz accionar no sufrió mayores consecuencias. Quedando únicamente en condición de "desembarcado"6 hasta que nuevos vientos soplaran a su favor.

4 Cfr. Holguín... ob.cit., Parte III, Cap. VII, pp.516-518.

5 Ibíd., pp. 523.

6 Ibíd., p.533. 
En el caso de Grau, como bien reflexiona en profundidad José Agustín de la Puente, sucedió otro tanto:

"¿Qué representa en la vida de Grau su participación en el levantamiento vivanquista? ¿Se perturban su personalidad, su visión de la Marina de Guerra y de la tarea que corresponde a un oficial? Toda respuesta puede llevar a hipótesis que pueden sostenerse con mayor o menor fundamento. Es posible pensar, sin embargo, que Grau sufre con esta revolución, en momentos distintos y de manera diversa. Primero al tomar la decisión, por las dudas que ha de haber considerado en su espíritu; luego durante el largo proceso de la revolución misma, por el hecho de reconocerse y sentirse contrario a la autoridad legítima, al Estado. Es posible deducir que esto, sumado al alejamiento de la Marina de Guerra, secuela de la revolución, siembra en él la semilla de cierto escepticismo; tal vez Grau se formula preguntas sobre los límites y alcances en el ejercicio del deber. En todo caso, esta revolución de Vivanco, primer contacto de Grau con la política peruana, es una experiencia que no se ubica entre los mejores recuerdos de su vida"7.

\section{Palma y Grau hermanos masones}

Aparte de las relaciones de trabajo o profesionales que Palma y Grau pudieron compartir como miembros de la Marina de Guerra del Perú, y eventualmente como parte del mismo bando revolucionario vivanquista, corresponde ahora ir por otro camino que nos hable de la estrecha relación de fraternidad que cultivaron ambos como hermanos masones. Asunto este que en sus correspondientes biografías resulta controversial y ha sido muchas veces silenciado por la gran

7 Cfr. De la Puente, José Agustín. Op.cit., Cap. IV, p.65. 
mayoría de sus biógrafos, quizá para no hacer caer sobre ellos mácula alguna.

Ya desde de la época virreinal ${ }^{8}$ y muy especialmente cuando se gestó la etapa de la Independencia de la América española, se encuentra la participación de una serie de personajes políticos, militares, literarios vinculados a la francmasonería. Es más, figuras como las del propio José de San Martín o la de Simón Bolívar están ligadas a este grupo ${ }^{9}$, considerado entonces y después, por el magisterio y las leyes de la Iglesia católica, como un grupo "sectario y maquinador" que estaba condenado expresamente por ella ${ }^{10}$.

No obstante, la condena expresa y pública que la masonería llevaba a cuestas, muchos personajes de la vida nacional peruana, abrazaron sus enseñanzas, códigos, vida y estilo. Unos con convencimiento real y pleno, otros como especie de "moda de conveniencia", ya que ser parte de esta especial "fraternidad" les aseguraba ascenso social y económico, sin importarles mucho las connotaciones y efectos que ella tuviera en lo religioso, moral y filosófico de su fuero interno. Quizá lo más atractivo de la masonería para sus adeptos era sus tentáculos con el poder. De este modo quien aspiraba a llegar un día a ocupar un puesto alto como magistrado, político, militar, diplomático u hombre de letras, etc., debía, sin duda, pensar en la filiación a alguna de las logias y "talleres" que existían tanto en el Callao como en Lima. Fue este, al parecer,

8 Véase Mendoza Silva, Eduardo, Historia de la masonería en el Perú /Masonería pre-republicana. Lima, Imprenta Rávago e hijos, s/f.

9 Véase Castro Olivas, Jorge Luis. El secreto de los libertadores. Lima, Editorial de la Universidad Ricardo Palma, 2011.

10 Las leyes de la Iglesia católica, desde sus constituciones apostólicas más antiguas hasta el denominado Codex Iuris Canonici vigente han condenado de modo específico a la masonería. Véase, por ejemplo, la Constitución Apostólica In eminenti de Clemente XII de 1738 o el vigente Código de Derecho Canónico de 1985, cánones números, 684, 2335 y 2336. 
el caso de nuestros personajes estudiados. Sobre la vinculación del tradicionista a la masonería, el estudioso nasqueño Julio Díaz Falconí, en el acápite titulado "La masonería abre muchas puertas" de su opúsculo Los padrinazgos de Ricardo Palma, dice:

"Palma accedió a la masonería en 1855, justo cuando completó 22 años, edad mínima exigida para pasar la prueba esotérica. (...) el venerable Maestro de aquella época, Manuel Cipriano Dulanto recibe e inicia a Ricardo Palma. (...) Palma nunca dijo que era masón. [Sin embargo,] en sus confabulaciones políticas hay hondas raíces masónicas. Se declara liberal, mas no masón, a pesar de que actuaba a la sombra de masones archiconocidos, como José Gálvez [Egusquiza], que luchaban contra el gobierno autoritario de Ramón Castilla. Aquél, como más poderoso, pasó su exilio en Francia. Palma, en cambio, como más desvalido, fue desterrado a Chile (...)"11.

Aunque la pertenencia a la masonería de Ricardo Palma ha sido estudiada por Alfonso Harth Bedoya desde 1992 y más recientemente por algunos otros investigadores ${ }^{12}$. La vinculación de Miguel Grau Seminario a este grupo no está aún bien iluminada desde la ciencia histórica. Inclusive hay quienes dudan de la pertenencia de Grau a este grupo. Uno de ellos es José Agustín de la Puente Candamo, quien en su magistral biografía: Miguel Grau, cuya primera edición es de 2003, escribe:

11 Cfr. Díaz Falconí, Julio. Los padrinazgos de Ricardo Palma. Trujillo, Papel de Viento Editores, 2007, p.45. Véase asimismo Adriazola Silva, Juan Carlos. "Don Ricardo y su hijo Clemente, dos desterrados políticos en tierras del Mapocho", en Aula Palma N ${ }^{\circ}$ XII. Lima, Editorial de la Universidad Ricardo Palma, 2013, pp.374-427.

12 Véase, por ejemplo, el interesante trabajo de Ismael Pinto Vargas "Don Ricardo Palma y la masonería” en Aula Palma XII, Lima, Instituto Ricardo Palma, 2013, pp.209-228. 
"No debo omitir una mención a la supuesta masonería de Miguel Grau. Sin embargo, la falta de testimonios y documentos originales que acrediten la voluntad de Grau de ingresar a la masonería, con su firma, impide hablar de un Grau masón. Además está presente el elocuente testimonio de su vida, que lo muestra como un católico que no oculta su creencia y la confiesa"13

Pese a lo manifestado por de la Puente, Manuel Zanutelli Rosas, investigador serio y prolífico, había publicado ya en 1996 un libro titulado Concordia Universal (Cien años de historia de una logia) en donde menciona con toda claridad que Miguel Grau y su íntimo amigo y paisano Lizardo Montero:

“(...) Fueron propuestos en la tenida del 16 de noviembre de 1859, ante la logia 'Virtud y Unión' Para pertenecer a sus 'augustos misterios"” 14 .

Por otra parte, es interesante advertir que en la información que Hart Bedoya ha dejado sentada en su libro Ricardo Palma. El egregio tradicionalista e ilustre masón peruano, al hablarnos de la filiación de Palma a la masonería pone de relieve que la logia "Concordia Universal" del valle del Callao no surgió de un momento a otro, sino que fue fruto de una agrupación previa, compuesta quizá toda por miembros de la Marina de Guerra del Perú, de allí la particularidad del nombre que se le dio. Al respeto se lee:

"[Ricardo Palma] se inicia en la señera y tradicional Logia del Callao "Concordia Universal" registrada con el $N^{\circ} 2$ en

13 Cfr. Puente Candamo, José Agustín de la. Miguel Grau. Lima, Instituto de Estudios Histórico Marítimos del Perú, 2003, Cap. XII, p.250, nota 3.

14 Cfr. Zanutelli Rosas, Manuel. Concordia Universal (Cien años de historia de una logia). Callao, 1996, p.108. 
el Gran Oriente Peruano y fundada el 20 de Setiembre de 1849, a raíz de la inquietud de numerosos hermanos que trabajaban agrupados bajo el nombre de "Unión con la Marina Peruana"15.

Retomando la filiación de Miguel Grau a la masonería, debe indicarse que entre los masones peruanos del presente y del pasado no cabe la menor duda de esta pertenencia al grupo de hombres "libres y de buenas costumbres", ya que tanto en libros, revistas, boletines, fotografías y pinturas que ellos exhiben en sus "talleres" internos y en los salones ceremoniales de sus logias está reservado siempre un lugar de honor muy especial para la figura del "Héroe de Angamos"(quien muchas veces aparece retratado incluso con el clásico mandil masónico). Y particularmente conmemoran la fecha de su natalicio (julio), el combate de Iquique (mayo) y su inmolación (octubre) como parte de su programa anual de actividades. He aquí un ejemplo patente de ello, en voz de Ricardo Jiménez Marotta:

"Una feliz iniciativa de Cruz Austral $N^{\circ}$ 12, mi madre Logia, hizo que, como un deber de conciencia masónica, y en concordancia con las disposiciones emanadas por la Muy Resp: Gran Log:.del Perú, un grupo de HH: de la fraternidad, rindiéramos el testimonio de nuestra admiración, respeto y veneración a la figura del egregio marino epónimo, nuestro muy Q:. H.: Miguel Grau Seminario, fiel exponente de los principios constante y pura de los más caros postulados de Amor, Caridad y Verdad, pilares fundamentales sobre los que descansa nuestra Augusta Orden. (...)

Su nombre estuvo ligado al "Huáscar", porque el "Huáscar" siempre estuvo ligado a Grau. No se sabe que más admirar

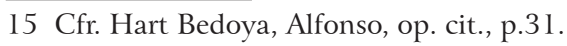


en él. Si su pericia en el combate o su caballerosidad. (...) $\mathrm{Su}$ figura se agiganta y la evocación del recuerdo de su acción con la viuda de Prat cobra caracteres insospechados cuando el marino cede paso al masón. Los trofeos no son tales para él. Grau recuerda que todos los hombres son sus hermanos y en cumplimiento de los sagrados principios que juró en el Ara escribe-... 'un sagrado deber me autoriza a dirigirme a Ud. y siento profundamente que esta carta, por las luchas que va a rememorar, contribuya a aumentar su dolor que hoy justamente, debe dominarla'(...)

[Al final del discurso, el orador concluye:] Que las pasiones del rencor, del odio y ambición no germinen en nuestros corazones; y que esta enseñanza de íntima y permanente renovación, deba constituir la fuente en que se nutra nuestro espíritu, para que por encima del materialismo evoquemos como un símbolo aquella figura egregia de Miguel Grau, permitiéndonos medir nuestros pensamientos y acciones con la escuadra de la Prudencia del G:.A:.D:.U:.y el compás de nuestra propia conciencia"16.

Leído lo anterior, cobra entonces pleno sentido lo que en el 2009, el investigador Jorge Monroy Gálvez, en interesante artículo publicado en la revista "Época" de Piura, escribe:

"Hoy, ya no podemos dudar de que al Gran Almirante del Perú: Miguel Grau Seminario, fue un Hermano Masón. $(\ldots) "$

Y más adelante agrega:

16 Cfr. Jiménez Marotta, Ricardo. "Miguel Grau”, en El Heraldo masónico. Órgano de la B:.R:.L:.S: CRUZ AUSTRAL N 12, del 28 de mayo de 1965. Asimismo, puede consultarse: Rubio, Carlos. "Homenaje a Miguel Grau", en Boletín. Órgano Informativo de la Gran Logia del Perú para los miembros de la Orden. Año IV, octubre-noviembre 1978, núm.46-47. 
"Durante su estada en Lima, [Grau] toma sincera amistad con el tradicionalista (sic) Don Ricardo Palma, Hermano Masón, con quien con frecuencia, visita la R:.L:.S:. Cruz Austral $\mathrm{N}^{\circ} 5$, en donde se familiariza y profundiza en sus prácticas y principios de la Franc Masonería (...)"17.

Si bien estas referencias bibliográficas, o fuentes de segundo orden como suele llamárseles en la historiografía, son las únicas que nos proporcionaban información sobre el tema, será recién a inicios de 2013 la fecha en la que los miembros de la masonería peruana decidieron sacar a la luz el documento que probaría de modo irrefutable la filiación masónica de don Miguel Grau Seminario. El documento lo hizo público Nicolás Roberto Ramírez Yánez, quien dio a conocer el resultado de una investigación realizada hacia el interior del Instituto de Estudios Históricos de la Gran Logia del Perú ${ }^{18}$. La información dice literalmente:

"El miércoles 15 de mayo de 2013, el M. R..$H$. . Hildebrando Eli Machuca Araujo, Gran Maestro de la Gran Logia del Perú, recibió de manos del R. $. H . \therefore$ Nicolás Roberto Ramírez Yánez, V. $\cdot$ M. $\therefore$ de la Logia Concordia Universal $\mathrm{N}^{0} 14$ ubicada en el Callao, una copia certificada del libro de actas de 1858 a 1868, y en ella hay una correspondiente al acta de la Tenida en que consta, la lectura de una que había recibido el 24 de noviembre de 1859, donde se hace de conocimiento que en la Tenida del 16 de noviembre de 1859, en la Logia Virtud y Unión $\mathrm{N}^{\circ}$ 3, habían sido propuestos dos candidatos, uno de ellos con el nombre de Miguel Grau y el otro como su

17 Cfr. Monroy Gálvez, Jorge. "Gran Almirante Miguel Grau Seminario /El hombre, el masón, el héroe”. En revista Época, núm.398, Año XLIV, octubrenoviembre, 2009.

18 Véase:http://www.glperu.org.pe/node/3056. Noticia del 22/5/2013. Consultado en Internet el 22/9/2014. 
compañero de armas y amigo entrañable, Lizardo Montero, de tal manera que fuera de conocimiento de todos los hermanos por si hubiera algún reparo respecto a las citadas personas.(...)".

Por una parte, esta información vendría a corroborar lo que diecisiete años antes afirmó Manuel Zanutelli en el libro antes mencionado. Y, por otra parte, aquella información da pie para afirmar ahora que uno de los posibles contactos entre Ricardo Palma y Miguel Grau fue la hermandad masónica, que ambos abrazaron en su momento y con algunos de los propósitos antes señalados. Es más, existe un detalle que en el caso de Grau, no puede dejar de mencionarse, y es que el padre del Gran Almirante del Perú, el cartagenero don Juan Manuel Grau y Berrío (quien murió en Valparaíso en 1865), al parecer, fue también masón según una nómina que registra Hart Bedoya ${ }^{19}$.

No deseo por ahora agotar el tema, pero, por lo menos, tenemos indicios claros de una posible amistad o contacto entre Palma y Grau, de la que no se sabía absolutamente nada hasta hace pocos años debido al gran secretismo con que los hermanos masones tratan sus asuntos corporativos.

\section{Homenajes literarios de Palma a Grau}

Como el resto de sus connacionales, don Ricardo Palma sintió la muerte del "Héroe de Angamos" muy cercana. Desde entonces siempre expresaría de él sus mejores frases y recuerdos. Un ejemplo de ello lo encontramos en su ensayo La bohemia de mi tiempo, cuando al hablar del poeta español Fernando Velarde, Gran "Capitán de la bohemia limeña” (1848-1860), que años

19 Cfr. Hart Bedoya, Op. cit, p.120. 
antes había sido en la capital peruana profesor del joven Miguel Grau, expresa:

"Cuando sonó para el Perú la hora de los grandes infortunios. Fernando Velarde envió desde Londres, su ofrenda para la corona fúnebre de Miguel Grau, el bravo marino que sucumbió heroicamente en el combate naval de Angamos; y con ella palabras de aliento y de consuelo que, en su espíritu, hallaban eco las angustias y desventuras de los peruanos"20

Pero más sentidas fueron las palabras del tradicionista con respecto a Grau, cuando después del combate de Angamos, versifica y crea una "Hoja de laurel" para darle cuerpo a su tristeza:

\section{MIGUEL GRAU}

"Sol de resplandor fecundo

Que nuestras pupilas hiere

Fue Miguel Grau; nunca muere

El astro-rey para el mundo.

¿A qué de duelo profundo

Llanto derramar sincero

Si ya, con buril de acero,

Grabó ese nombre la Fama,

Y el mundo la gloria aclama

Del héroe y del caballero?

Vive la vida inmortal

Que conquistó su heroísmo:

No se hundirá en el abismo

Del olvido nombre tal

20 Cfr. PALMA, Ricardo. "La bohemia de mi tiempo". En Tradiciones peruanas completas, Madrid. Ediciones Aguilar, 1957, pp.1295-1296. 
Del tiempo el giro fatal

Dará más irradiación

A tanta espléndida acción,

Y del Héroe la memoria

Honra será de la historia,

Gala de la tradición"21.

\section{El homenaje marmóreo de Palma y su gestación en 1905}

Finiquitada la Guerra del Pacífico con el Tratado de Ancón de 1883, el nombre y la egregia figura del comandante del Huáscar, don Miguel Grau Seminario siguió creciendo con los años en el imaginario colectivo de los peruanos y, especialmente, en el de los piuranos que recordaban a su paisano como defensor de la dignidad nacional. En 1906, era Prefecto de la ciudad de Piura, don Germán Leguía y Martínez, primo-hermano de quien poco después, entre 1908 y 1912, y luego entre 1919 y 1930 , conduciría los destinos de la nación: don Augusto Bernardino Leguía y Salcedo. En dichos períodos gubernativos, don Germán Leguía y Martínez llegaría a ocupar importantes cargos, como el de Ministro de Estado en la cartera de Relaciones Exteriores.

Germán Leguía y Martínez ${ }^{22}$ nació en Lambayeque en 1861 y ha pasado a la historia nacional, a la par de hombre público, como un estudioso de diversos asuntos y personajes notables vinculados a nuestra patria. Fue, en esencia, educador, abogado, escritor y periodista. Pocos saben quizá que su padre, el fiscal don Germán Leguía y $\mathrm{Haro}^{23}$, lo trajo muy niño a vivir a Piura, y desde entonces fue un enamorado de su geografía, de sus costumbres,

21 Cfr. Compton, Merlin (Compilador). Obra poética de Ricardo Palma. Lima, Biblioteca Nacional del Perú, 2000, p.500.

22 Los datos biográficos sobre este personaje se han tomado de: ANUARIO LAMBAYEQUE-PIURA, 2da. edición, Impreso en Chiclayo en 1948, pp.672.

23 El fiscal Germán Leguía y Haro se halla enterrado en el cementerio San Teodoro de Piura. 
de la bonanza que el departamento vivía por aquellos años (caracterizada por fértiles haciendas, construcción de grandes canales de regadío, volúmenes notables de producción agrícola y ganadera) y, por supuesto, de los más importantes personajes que marcaron hitos en su devenir histórico ${ }^{24}$.

Germán Leguía y Martínez fue designado en el cargo de Prefecto del Departamento de Piura (1905-1908) durante el primer período gubernativo del presidente José Pardo y Barreda. Se acopló rápido a las costumbres locales, pues sus antiguos contactos y cercanía a familias norteñas le abrieron pronto las puertas de la sociedad piurana. En el deseo de hacer obra importante durante su gestión y, al mismo tiempo, coadyuvar con la cultura local, tomó noticia de la casa en donde la tradición oral de los viejos piuranos aseguraba había nacido el Héroe de Angamos, pues en ese inmueble había vivido permanentemente su propietaria doña Luisa Seminario del Castillo, madre de don Miguel Grau. Con ese propósito, dio los primeros pasos para crear conciencia de la importancia que guardaba dicho inmueble para la historia de Piura, sin embargo, ese afecto se debía concretar en una manifestación visible a los ojos de todos: una placa de mármol consideró era lo ideal. Pero lograr esta no fue, en principio, fácil. La circunstancia de su confección, se dio más bien por otro asunto histórico.

En 1906 el gobierno peruano inauguraría en Lima el monumento a don Francisco Bolognesi, para ello vendría

24 Su obra más notable lleva por título: Diccionario geográfico, histórico, estadístico del departamento de Piura.- Lima, Tip. El Lucero, 1914, pp.320. Aunque el plan de la obra comprendía varios tomos sucesivos, en realidad solo pudo editar el primero de ellos, que comprendía las palabras ordenadas alfabéticamente de la "A" hasta la "CH". Este Diccionario contiene mucha información de primera mano, recogida durante sus numerosos viajes hacia el interior del departamento. La obra resultante justifica el deseo expresado por el autor en la p. VI de la introducción: "Ojalá que los prefectos, todos, acometiesen trabajo semejante en sus respectivos departamentos". Los otros tomos de ese Diccionario, aunque fueron redactados, han quedado inéditos. 
invitado especialmente desde Argentina el doctor Roque Sáenz Peña, el General sobreviviente que peleó al lado del Héroe de Arica. Dicho General argentino, y por ley del Congreso de 1905, también General del Perú, contaba con la admiración y respeto de la mayoría de peruanos. Don Germán Leguía y Martínez pensó entonces que los piuranos no podían ser indiferentes ante los diversos homenajes nacionales que se tributarían al hijo predilecto del Río de la Plata. Sobre el particular, el diario "El Sol", núm.17 del jueves 19 de octubre de 1905, dice en su página núm. 2:

“Todos los departamentos de la República, con mayor o menor esplendidez, en ésta o aquella forma, pero con espontánea y unánime explosión de gratitud y patriotismo, han resuelto enviar al abnegado argentino, defensor del Perú y héroe de Arica general Dr. D. Roque Sáenz Peña, alguna prenda del reconocimiento nacional, que al mismo tiempo sea humilde agasajo de bienvenida a muestra visible del regocijo con que las secciones todas de la República reciben el arribo al territorio del huésped por mil modos y motivos querido y admirado.

¿Sólo Piura, la patria de Grau, sería una excepción oprobiosa en movimiento semejante? Imposible! ¿Qué se diría si su alto nombre faltase en la grandiosa lista de ofrendas que a los pies del gran argentino depositen los pueblos de la República? Debe dar vergüenza el pensarlo, y urge alzarse como un solo hombre a fin de preparar el modesto, pero cariñoso presente de hija primogénita de Pizarro".

Para concretar la idea se empezó entonces una suscripción en donde participaron los piuranos de todos los estratos sociales. El total de dicha colecta fue de S/.416.60 soles de la época. La confección de la medalla de oro costó finalmente S/. 298.00, y quedó un remanente de S/.118.60. La pregunta que se 
hicieron los organizadores de la suscripción era ¿qué se haría con esta suma? Germán Leguía y Martínez había pensado en un homenaje a Miguel Grau y al lugar en donde, por sus investigaciones y siguiendo la tradición de los viejos piuranos, se decía había nacido el "Caballero de los Mares". Esta idea quiso compartirla con una persona de experiencia: don Ricardo Palma. Por ese motivo escribió al tradicionista, a quien conocía y admiraba desde años antes, cuando estudió en Lima la carrera de Jurisprudencia. En carta de respuesta que el tradicionista fechó el 20 de mayo de 1906, escribe:

"Con respecto a la consulta que usted, mi apreciado amigo, me formula, acerca de un homenaje a Miguel Grau, el más excelso de nuestros héroes nacionales, estoy plenamente de acuerdo con usted. Cualquier homenaje es poco para él. Si hubiera que aterrizar una idea, lo más aconsejable es que se haga un buen mármol conmemorativo. Así las generaciones del presente y del futuro, como en la Antigüedad clásica dieron ejemplo notable los romanos, podrán, quienes transiten por esa calle, saber el lugar exacto en el que nació el hijo más preclaro de esa tierra".

Pensó don Germán Leguía y Martínez que el texto que se grabaría en la placa marmórea debía ser asimismo escrito por don Ricardo Palma a quien le escribió apelando a su espíritu patriótico. El padre de las Tradiciones Peruanas, entonces Director de la Biblioteca Nacional, aceptó gustoso el encargo. El diario El Sol en su edición núm. 244 de 27 de julio de 1906 cuenta algunos detalles sobre el particular:

"Llegó en el vapor venido ayer del sur, i en tren de hoi (sic) será conducida á esta ciudad, la plancha conmemorativa que va a colocarse en la casa donde nació esa gloria de Piura MIGUEL GRAU. 
Había sido hecha con el dinero sobrante de la suscrición (sic) levantada para obsequiar una medalla al general Roque Sáenz Peña, i tan pronto como se conozcan i paguen los gastos de transporte, se publicara la cuenta respectiva.

La plancha respectiva es de mármol, mide cm. $100 \times$ X 75, i ha sido labrada por la acreditada casa Roselló de Lima, bajo la dirección de otra gloria nacional i aun americana RICARDO PALMA.

Como éste lo expone en la carta pertinente, se ha prestado con la mayor buena voluntad á servir esta vez a Piura, ciudad que le es altamente simpática; como ya la sirvió en otra ocasión encargada de construir el monumento al gran pintor Ignacio Merino".

La inscripción redactada por el tradicionista y, posteriormente, grabada sobre el albo mármol de Carrara, dice en letras negras de bajo relieve:

EN 27 DE JULIO DE 1834

NACIO EN ESTA CASA EL CONTRALMIRANTE

MIGUEL GRAU

QUIEN MURIO HEROICAMENTE

A BORDO DEL MONITOR

HUÁSCAR

EN EL COMBATE NAVAL DE ANGAMOS

EL 8 DE OCTUBRE DE 1879

SE COLOCÓ ESTE MARMOL CONMEMORATIVO

EL 28 DE JULIO DE 1906 
Respecto a su contenido textual de la placa, el periodista de "El Sol" expresaba:

"Inscripción sencilla como todas las de su clase. La obra es modesta, y debe aceptarse por lo que tiene de glorioso i significativo para este noble suelo, en que vinieron al mundo tantos hombres grandes. Algún día será reemplazado el mármol por el bronce; pero, entretanto, queda en lo posible atendido ese vacío, colmado hoi (sic) para el legítimo orgullo i el acendrado patriotismo de los piuranos.

El Sol en nombre de Piura, envía sus aplausos i agradecimiento al Patriarca de las letras patrias. Valioso es el servicio: Piura no ha de olvidarlo"25.

La llegada de la ansiada placa de mármol se comunicó a la población piurana, mediante un aviso publicado en la sección "Sueltos Editoriales" del diario "El Sol", gracias a la información que, desde el puerto de Paita, remitiera el día 23 de julio de 1906, el corresponsal de dicho diario, quien escribe:

"Si en el vapor Santiago, que hoi (sic) amaneció fondeado en el vecino puerto, ha cumplido como no puede dejar de suceder, nuestro gran literato don Ricardo Palma, con enviar la plancha de mármol indicativa del sitio donde nació el glorioso Grau, la colocación de ese objeto conmemorativo adicionará brillantemente el programa [de su septuagésimo natalicio]. iI dirán los malos agoreros que vamos hacia atrás!"26.

25 Cfr. Diario "El Sol" de Piura, núm. 244, del 27 de julio de 1906.

26 Cfr. Diario "El Sol" de Piura, núm. 242, del 26 de julio de 1906. 
Confirmada la llegada de la placa a la estación del tren que unía Paita con Piura, el prefecto Leguía empezó a hacer los ajustes al Programa especial que, con motivo del septuagésimo segundo aniversario del natalicio de don Miguel Grau Seminario, se llevaría a cabo el día 3 I de julio de 1906, y no el 28 como inicialmente estaba prevista, pues se deseaba contar con la presencia efectiva y la colaboración de la Municipalidad de Piura y de las principales corporaciones de la ciudad.

Escribió para ello a don Pedro Enrique Arrese y Paredes ${ }^{27}$, creyéndolo propietario de la casa, pues en realidad la legitima propietaria del inmueble era su esposa doña Luz Vegas León de Arrese, hija y heredera de don Fernando Vegas Seminario, antiguo comprador de la casa a los hermanos Roberto y Emilio Días Seminario, quienes la heredaron de su madre Luisa Seminario del Castillo $^{28}$, madre de Héroe de Angamos. El señor Arrese era un rico agricultor de la región, dueño, entre otras propiedades, de la hacienda Mallares, lugar en el que permanecía por largas temporadas, supervisando sus cultivos y el engorde de su ganado. El prefecto Leguía en prudente carta remitida por vía telefónica, le decía al señor Arrese:

"La casa en que habita Ud. i que, si no me equivoco es de su propiedad, tuvo la gloria de ver nacer á Miguel Grau.

27 Particular importancia tiene el nombre de don Pedro Enrique Arrese y Fernández de Paredes, quien en sus años mozos como representante de La Huaca fue uno de los 38 electores de Miguel Grau como diputado por Paita ( 16 de noviembre de 1875). Esta información la proporcionó Miguel Arturo Seminario Ojeda en el artículo "Los electores de Miguel Grau”, en Suplemento SEMANA de El tiempo de Piura, domingo, 26 de octubre de 2014, pp.16-17.

28 Doña Luisa Seminario del Castillo posiblemente se trasladó de Piura a Lima a mediados de 1873, aquejada por alguna enfermedad grave. Era mujer acaudalada y repartió sus bienes entre los descendientes que creyó conveniente, mediante testamento que firmó el 5 de diciembre de aquel año, según documento que redacta el escribano Félix Sotomayor. Cfr. Archivo General de la Nación. Protocolo N 866. / Escritura Pública N²044, f. 98 lv. 
Habiendo hecho labrar una plancha marmórea, indicativa del lugar en que se efectuó ese memorable acontecimiento, solicito a Ud. el necesario permiso para colocarla i llevar á cabo la ceremonia correspondiente.

Esperando una favorable respuesta de su notorio patriotismo, aprovecho esta grata oportunidad para ofrecer á Ud. las seguridades de mi consideración distinguida i personal estimación. Dios guarde a Ud. Germán Leguía i Martínez"29.

Desde la hacienda Mallares (Sullana), Arrese contesta telegráficamente al Prefecto de Piura:

"Sábado a las 3h. 10m. PM. Sr. Prefecto. Piura. El oficio de US. se me ha transcrito por teléfono. Proceda US., sin necesidad de permiso á la colocación, en casa, de la lápida de mármol que recuerde el nacimiento del héroe Miguel Grau, cuya memoria veneramos todos.

Felicito á US. por idea tan patriótica, que Piura recordará siempre. Iré a Piura el día de la ceremonia. Saluda respetuosamente á US. Pedro E. Arrese" 30 .

Realizadas todas las coordinaciones, el Programa celebratorio se realizó conforme a lo acordado. En el antiguo diario El Sol de Piura ${ }^{31}$, núm. 246, editado el miércoles 1 de agosto de ese año, se lee:

29 Cfr. Diario "El Sol" de Piura, núm. 250, lunes, 6 de agosto de 1906.

30 Loc. cit.

31 Uno de los periódicos fundados en Piura por Germán Leguía y Martínez fue el diario "El Sol", que logró editar gracias a la ayuda invalorable de los hermanos Benjamín y Antenor Rosas, propietarios de los talleres de impresión. Cfr. RAZURI, José Vicente. Recuerdos piuranos. Lima, TIPOART, 1961, p.64. 
"[Se reunieron] en la casa prefectural todas las corporaciones i personas que el día 28 habían con su presencia realizado la asistencia oficial. Acudió de gran parada el escuadrón $\mathrm{N}^{\circ}$ 5, i á las 3.30p.m. la numerosa escogida comitiva púsose en marcha. Precedíanla cuatro gendarmes, conductores de la lápida alusiva, cuyos pormenores e inscripción dimos días pasados; i, llegada á la plaza de armas por el jirón de San Francisco ó Lima, dirigiose á la calle adyacente al Cabildo en que está situada la casa del Sr. Pedro Enrique Arrese i Paredes, que es la misma en que nació el gran héroe de Piura, en la habitación de la diestra, junto á la ventana. Entre ésta i la puerta principal, á una altura conveniente, para poner la inscripción lejos del alcance de los perversos ó profanos; estaba listo el marco en que debía ser entornillada esa modesta ofrenda de un pueblo orgulloso y agradecido, al más grande de sus defensores i mártires.

La calle ofrecía, al llegar las corporaciones, el golpe de vista más encantador llenas de gente, las puertas y ventanas vecinas, convertidos los balcones en cestas de flores bellísimas i fragantes, en especial los de la casa histórica, en la cual parecían haberse dado cita [un coro] de diversos ángeles $(\ldots)$.

Don Germán Leguía y Martínez, organizador principal de la ceremonia de inauguración de la, desde entonces, llamada "Casa de Grau" de Piura, pronunció un solemne y vibrante discurso que a la letra dice:

"La América lo venera, el mundo lo admira, no hay corazón peruano que no se abra ante su nombre como un templo, i vierta ante su gloria el incienso de una gratitud i un orgullo tan legítimo como perdurable.

Bendito sea! Bendita sea la tierra que lo vio nacer!

Bendito sea el rincón en que meció su cuna venerada. 
I esa tierra es Piura: regocijémonos! I ese rincón está allí delante de nosotros. Descubrámonos: I, como nosotros nos descubrimos llenos de patriótica emoción, descúbrase el viajero que en esa lápida conmemorativa lea la sencilla inscripción trazada por la esplendente pluma de Ricardo Palma: AQUí NACIÓ MIGUEL GRAU! ${ }^{32}$.

Es suficiente, no hay nada más que decir! Ese nombre basta!

La gloria es derecho de quienes, como el ave bíblica, brindaron el pecho al último sacrificio para vida i redención de sus hermanos, i es deber ineludible para los que con ese sacrificio, ganaron honra y noble ejemplo que se eternice en las edades.

Dichoso pueblo ese que, como la madre de los $\mathrm{Gracos}^{33}$, puede decir al mundo: Mis joyas son mis hijos. I más dichoso, si puede agregar como Piura: He aquí a uno de esos hijos: Miguel Grau".

\section{A su turno el Alcalde de la ciudad de Piura, don Hugo Sommerkamp, expresó también el sentir de la comuna piurana, con estas sencillas palabras:}

“(...) Esta plancha quedará bajo el amparo del H[onorable] Concejo que tengo la honra de presidir i en ella se venerará una vez más el recuerdo de aquel valiente cuyo solo nombre significa patriotismo i lealtad".

32 En realidad, la placa no tiene grabada esta frase que refiere Germán Leguía Martínez en su discurso, quizá en la carta de respuesta que le envía Ricardo Palma desde Lima sí esté la mencionada frase, pero no ha sido ubicada a pesar de nuestros innumerables esfuerzos.

33 El nombre refiere a la mujer o madre que dio origen de la rama de la familia Sempronia y a la cual pertenecieron generales y políticos célebres de la vida romana, tales como, Tiberio Sempronio, Cayo Sempronio, etc. 
A renglón seguido correspondió, de acuerdo con el programa establecido, la intervención del "propietario" del inmueble don Pedro Enrique Arrese y Paredes, quien en henchido discurso manifestó:

“Señor Prefecto, señor Alcalde, señores:

Recibo agradecido esta plancha radiosa que, como dice con brillo i galanura, condensa un justo orgullo para Piura i cristaliza gloria imperecedera para la patria.

De hoi (sic) en adelante, esta mansión de mis hijos guardará con religioso respeto ese depósito sagrado, que simboliza el más heroico, el más noble, el más generoso sacrificio consumado en aras del amor á la patria.

El Perú no dirá jamás cuánto merece Miguel Grau, aun cuando agote los tesoros de su corazón agradecido; porque á medida que de los labios de sus conciudadanos brotan, á raudales frases de admiración, de cariño, de honda simpatía por su cruento sacrificio, su figura se acrecienta, la aureola de esplendor que lo rodea anubla la mirada i el corazón de la patria se deshace en llanto, guardándolo su dolor con el religioso recogimiento que ofrece el espectáculo sublime de su muerte, que, por uno de esos misteriosos designios de la Providencia, la metralla enemiga convirtió en polvo, que los vientos debían esparcir por todos los ámbitos de su patria idolatrada, para redimirla de su infortunio."

$\mathrm{Al}$ concluir la ceremonia en el frontis de la que, a partir de ese momento la gente empezaría a llamar la "Casa de Grau", las autoridades locales y los invitados especiales ingresaron en el salón de la residencia donde fueron agasajados por la familia Arrese.

Así concluyó el día en que en la ciudad de Piura se develó públicamente la placa de mármol que, desde Lima, envió don 
Ricardo Palma en homenaje a don Miguel Grau Seminario, su antiguo compañero en la Marina de Guerra del Perú y querido hermano masón. Este año, dicho recuerdo conmemorativo ha cumplido 108 años de vida, y al parecer por muchos años más seguirá señalándole a los piuranos el lugar donde nació el más heroico y abnegado defensor de la patria.

\section{Bibliografía}

ADRIAZOLA SILVA, Juan Carlos (2013). "Don Ricardo y su hijo Clemente, dos desterrados políticos en tierras del Mapocho", en Aula Palma $\mathrm{N}^{\circ}$ XII. Lima, Editorial de la Universidad Ricardo Palma, pp.374-427.

ARCHIVO GENERAL DE LA NACIÓN. Protocolo Nº66. / Escritura Pública No2044, f. 981 v.

ARENAS PÉREZ, Víctor (1948). Anuario Lambayeque-Piura. 2da. edición. Chiclayo, Editorial "Minerva".

BARREDA, Felipe A. (1959). El Caballero de los Mares Almirante Miguel Grau. Lima, Edición Privada.

CASTRO OLIVAS, Jorge Luis (2011). El secreto de los libertadores. Lima, Editorial de la Universidad Ricardo Palma.

CÓDIGO DE DERECHO CANÓNICO DE LA IGLESIA CATÓLICA (1985). Cánones números, 684, 2335 y 2336.

COMPTON, Merlin (2000). Obra poética de Ricardo Palma. Lima, Biblioteca Nacional del Perú.

DIARIO "El SOL" de Piura, núm. 242, del 26 de julio de 1906; núm. 244, del 27 de julio de 1906; núm. 250, lunes, 6 de agosto de 1906.

DÍAZ FALCONÍ, Julio (2007). Los padrinazgos de Ricardo Palma. Trujillo, Papel de Viento Editores. 
ESTREMADOYRO NAVARRO, Alfonso (1991-1993). "Las dos casas del Gran Almirante Miguel Grau, héroe de Angamos". En Revista del Instituto de Estudios Histórico Marítimos del Perú, Lima, Instituto de Estudios Histórico Marítimos del Perú, núms. 10-11, pp. 141-162.

GARAY ALBUJAR, Andrés. "El rescate de una Piura perdida" en suplemento Semana de diario El Tiempo, domingo 28 de abril de 2009, pp.11-14.

GRAU UMLAUFF, Fernando (2014). El entorno familiar de Miguel Grau Seminario. (Folleto que transcribe el discurso de incorporación del autor al Instituto de Estudios Histórico Marítimos del Perú, el 20 de febrero de 2014). Lima, Asociación Nacional Pro Marina del Perú, IEHMP y Dirección de Hidrografía y Navegación, 2014.

HART BEDOYA, Alfonso (1992). Ricardo Palma. El Egregio Tradicionalista e ilustre Masón Peruano. Lima, Editorial San Marcos.

HAMPE MARTINEZ, Teodoro (2013). Miguel Grau, protagonista político. Piura, Fondo Editorial Municipalidad Provincial de Piura y Caramanduca Editores.

HOLGUín CALlO, Oswaldo (1994) Tiempos de infancia y de bohemia. Ricardo Palma (1833-1860). Lima, Fondo Editorial de la PUCP.

JIMÉNEZ MAROTTA, Ricardo. "Miguel Grau”, en El Heraldo masónico. Órgano de la B:.R:.L:.S:. CRUZ AUSTRAL $\mathrm{N}^{\circ} 12$, del 28 de mayo de 1965.

LEGUÍA Y MARTÍNEZ, Germán (1914).Diccionario geográfico, histórico, estadístico del departamento de Piura.- Lima, Tip. El Lucero.

MARINA DE GUERRA DEL PERÚ (1984). A la gloria del Gran Almirante del Perú Miguel Grau. Lima. Ministerio de Marina.

(1964). "Solar donde nació Miguel Grau entregan a Casa de la Cultura de Piura”, en Revista de Marina, núm.4, julio-agosto, pp.486-488.

MENDOZA SILVA, Eduardo (s/f), Historia de la masonería en el Perú / Masonería pre-republicana. Lima, Imprenta Rávago e hijos. 
MIRÓ QUESADA SOSA, Aurelio (1973) Piura en las tradiciones de Palma. (Colección Algarrobo $N^{\circ} 11$ ) Piura, Universidad de Piura.

MONROY GÁLVEZ, Jorge (2009). “Gran Almirante Miguel Grau Seminario /El hombre, el masón, el héroe”. En revista Época, núm.398, Año XLIV, octubre-noviembre.

PALMA, RICARDO (1957). "La Bohemia de mi tiempo", en Tradiciones Peruanas Completas. Madrid, Ediciones Aguilar, pp.1295-1296.

PAZ VELÁSQUEZ, Juan Gabriel (2002). Piura: la cuna de Grau. Piura, edición privada.

PINTO VARGAS, Ismael (2013) "Don Ricardo Palma y la masonería" en Aula Palma XII, Lima, Instituto Ricardo Palma, pp.209-228.

PUENTE Y CANDAMO. José Agustín de la (2003). Miguel Grau. Lima, Instituto de Estudios Histórico-Marítimos del Perú.

ROBleS RÁZURI, Carlos (1981). "La Casa del Almirante Grau" / Casonas Piuranas. En diario "El Tiempo" de Piura, domingo 8 de marzo, p.10.

RÁZURI, José Vicente (1961). Recuerdos piuranos. Lima, TIPOART.

ROMERO PINTADO, Fernando (1984). Grau: biografía lírica. Lima, Dirección de Intereses Marítimos, Ministerio de Marina.

RUBIO, Carlos (1978). "Homenaje a Miguel Grau", en Boletín. Órgano Informativo de la Gran Logia del Perú para los miembros de la Orden. Año IV, octubre-noviembre, núm.46-47.

SEMINARIO OJEDA, Miguel Arturo (2014). "Los electores de Miguel Grau”, en Suplemento SEMANA de El tiempo de Piura, domingo, 26 de octubre, pp.16-17.

TEMPLE AGUILAR, Ella Dumbar (1979). El victorial de Miguel Grau. Lima, Separata de la Revista de la Universidad Nacional Mayor de San Marcos, núm. 20. 
THORNDIKE LOSADA, Guillermo (2005). Grau / Los hijos de los libertadores. Tomo 1, Lima, Fondo Editorial del Congreso del Perú y Fondo Editorial del Banco de Crédito del Perú.

ZANUTELLI ROSAS, Manuel (1996). Concordia Universal (Cien años de historia de una logia). Callao.

ZÚÑIGA SEGURA, Carlos (2004). Ricardo Palma en la Marina. Lima, Editorial de la Universidad Ricardo Palma.

\section{Página Web}

http://www.glperu.org.pe/node/3056. Noticia del 22/5/2013. Consultado en Internet el 22/9/2014. 